doi: $10.18004 / \mathrm{rdn} 2016.0008 .02 .094-100$

Caso Clinico / Case Report

\title{
Síndrome urémico hemolítico atípico asociado a neumococo
}

\section{Pneumococcal hemolytic uremic syndrome}

\section{Avelina Victoria Troche ${ }^{1}$}

\section{Gloria Celeste Samudio Domínguez ${ }^{2}$}

\section{Lidia María Ortiz Cuquejo 3}

1Servicio de Nefrología. Hospital Central. Instituto de Previsión Social. Asunción, Paraguay

2Servicio de Infectología. Hospital Central. Instituto de Previsión Social. Asunción, Paraguay

3Departamento de Policlínica. Hospital Central. Instituto de Previsión Social. Asunción, Paraguay

\section{RESUMEN}

El síndrome urémico hemolítico (SUH) es una entidad caracterizada por la tríada de insuficiencia renal aguda, anemia hemolítica no inmune y trombocitopenia. Se distinguen 2 tipos: el SUH típico o D (+) asociado a toxina Shiga y el atípico o D(-) entre los que se encuentra el SUH asociado a neumococo. Ésta es una patología poco común con alta morbimortalidad. Se presenta el caso clínico de un lactante que desarrolló un SUH asociado a neumococo en el marco de enfermedad neumocóccica invasiva

Palabras claves: neumococo, síndrome urémico hemolítico, vacuna antineumocóccica, lactante

\section{ABSTRACT}


Hemolytic uremic syndrome (HUS) is an entity characterized by the triad of acute renal failure, nonimmune hemolytic anemia and thrombocytopenia. Two types are distinguished: the typical HUS or D (+) related to Shiga toxin and the atypical or D (-) among which the HUS associated with pneumococcus. This is an uncommon pathology with high morbidity and mortality. We present the case of an infant who developed an HUS associated with pneumococcus in the contex of invasive pneumococcal disease

Key words: pneumococcal, hemolytic uremic syndrome, pneumococcal vaccine, infant

Fecha de recepción: setiembre 2016

Fecha de aceptación: noviembre 2016

Autor correspondiente: Avelina Victoria Troche. Servicio de Nefrología. Hospital Central. Instituto de Previsión Social, Paraguay. Correo electrónico: avtroche@yahoo.com.ar

\section{NTRODUCCI ÓN}

El SUH es una entidad caracterizada por la tríada de insuficiencia renal aguda, anemia hemolítica no inmune y trombocitopenia(1,2). La lesión anatomopatológica que le caracteriza consiste en un estrechamiento de las paredes arteriolares y capilares producida por la presencia de células endoteliales prominentes y edematosas con acumulación subendotelial de proteínas y la presencia de trombos plaquetarios con obstrucción de la luz $\operatorname{vascular}^{(2,3)}$. El paso de los glóbulos rojos a través de la pared vascular alterada produce la anemia hemolítica, mientras la trombocitopenia se produce por adhesión plaquetaria al endotelio dañado y la lesión renal es ocasionada por microangiopatía ${ }^{(1,2,4)}$. 
Desde el punto de vista laboratorial, la anemia se caracteriza por la presencia de eritrocitos fragmentados (esquistocitos) en el frotis de sangre periférica, niveles de LDH elevados en suero y haptoglobina baja $^{(1,2,4)}$.

Se describen 2 tipos de SUH: el SUH típico o D (+) que se asocia generalmente a diarrea por Escherichia coli productora de toxina Shiga (STEC), que corresponde al $90 \%$ de los casos y el SUH atípico o D (-) que se trata de un conjunto de condiciones clínicas que no están relacionadas con $\operatorname{STEC}(1,6)$.

Se presenta el caso clínico de un lactante que desarrolló un SUH asociado a neumococo en el marco de enfermedad neumocóccica invasiva.

\section{CASO CLÍ NI CO}

Varón de 1 año y 7 meses, con historia de 8 días antes del ingreso de rinorrea acuosa y fiebre de $39^{\circ} \mathrm{C}$, intermitente, sin escalofríos, que fue medicado con dipirona.

Cuatro días antes del ingreso presentó dificultad respiratoria progresiva que le impide el sueño y la alimentación, además: decaimiento e inapetencia. Dos días antes del ingreso presentó vómitos, precedidos de náuseas, de aspecto bilioso, en 3 oportunidades y disminución de la diuresis. Pero 18 hs antes del ingreso presentó anuria, por lo que fue ingresado en un Centro asistencial desde donde fue derivado al Hospital Nacional.

Examen físico: ingresa pálido, en mal estado general, con inestabilidad hemodinámica, hipotenso, intubado, con buena expansibilidad torácica. Frecuencia cardíaca 148/min. Pulsos débiles, llenado capilar 2 seg PAM: $49 \mathrm{~mm} \mathrm{Hg}$. En los pulmones se auscultan crepitantes y soplo tubario en base de pulmón derecho. Requiere asistencia respiratoria mecánica e 
inicia inotrópicos (dopamina, dobutamina y noradrenalina) con monitorización invasiva de la presión arterial.

Laboratorio: hemograma: hemoglobina $4,9 \mathrm{~g} / \mathrm{dL}$, hematocrito $14 \%$, glóbulos blancos $15.000 \mathrm{~mm}^{3}$, neutrófilos segmentados $65 \%\left(9750 \mathrm{~mm}^{3}\right)$, linfocitos $19 \%\left(2850 \mathrm{~mm}^{3}\right)$, eosinófilos $1 \%\left(150 \mathrm{~mm}^{3}\right)$, mielocitos $2 \%$ $\left(300 \mathrm{~mm}^{3}\right)$, metamielocitos $3 \%\left(450 \mathrm{~mm}^{3}\right)$, neutrófilos en banda $10 \%$ $\left(1500 \mathrm{~mm}^{3}\right)$, plaquetas $50.000 \mathrm{~mm}^{3}$. VSG $1^{\circ} \mathrm{h} 120 \mathrm{~mm}$. Poiquilocitos $(++++)$, esquistocitos $(+++)$. Procalcitonina $101,33 \mathrm{ng} / \mathrm{mL}, \quad P C R$ 192mg/L, LDH 948 UI/L. Na $135 \mathrm{mEq} / \mathrm{L}, \mathrm{K}$ 3,4 mEq/L, Cl 98 mEq/L . Tiempo de protrombina 84,5\%, INR 1,13, fibrinógeno $462 \mathrm{mg} / \mathrm{dL}$, proteínas totales $4,9 \mathrm{~g} / \mathrm{dL}$, albúmina $2 \mathrm{~g} / \mathrm{dL}$, urea $203 \mathrm{mg} / \mathrm{dL}$, creatinina $1,96 \mathrm{mg} / \mathrm{dL}$. Hemocultivo: positivo para Streptoccocus pneumoniae sensible a penicilina, cefotaxima, trimetoprim-sulfametoxazol, vancomicina.

Gasometría arterial: pH 7,17; $\mathrm{pCO}_{2} 62 \mathrm{~mm} \mathrm{Hg}, \mathrm{pO}_{2} 71,2 \mathrm{~mm} \mathrm{Hg}$, EB -5,3 $\mathrm{mmol} / \mathrm{L}, \mathrm{HCO}_{3} 19,5 \mathrm{mmol} / \mathrm{L}$, sat $\mathrm{O}_{2} 94,4 \%$.

Radiografía y tomografía de tórax: condensación en base de pulmón derecho con imágenes de bullas y derrame pleural. Ecografía pleural: derrame pleural derecho, asociado a la presencia de fino material ecogénico en suspensión y a la hepatización del parénquima pulmonar homolateral. Ecocardiograma: anatomía intracardíaca y del arco aórtico normales, hipertensión pulmonar, ausencia de derrame pericárdico, cámaras cardíacas de dimensiones normales, ausencia de trombos o vegetaciones. Ecografía renal: riñones de tamaño y ecogenicidad aumentada con pérdida de la diferenciación córticomedular.

Los diagnósticos de ingreso fueron: neumonía necrotizante bilateral con derrame pleural derecho, choque séptico con falla de múltiples órganos, SUH asociado neumococo.

Requirió trasfusión de plaquetas para colocación de tubos de drenaje pleural y de diálisis peritoneal y de glóbulos rojos concentrados y plasma 
por la inestabilidad hemodinámica. Se inició antibioticoterapia con cefotaxima+clindamicina+vancomicina.

La antibioticoterapia se rotó a imipenem+amikacina por sospecha de infección asociada a cuidados de la salud y luego a tigeciclina+ colistina+anfotericina B por aislamiento de Acinetobacteri wofii en punta de catéter. Ante la presencia de Estenotrophomonas maltofilia en secreción traqueal recibió trimetoprim-sulfametoxazol.

Requirió asistencia respiratoria mecánica por 19 días y drenaje pleural por 29 días por derrame pleural y neumotórax por rotura de bullas.

Recibió 5 sesiones de diálisis peritoneal intermitente, con recuperación total de la función renal. Fue dado de alta a los 31 días en buen estado general y actualmente está en seguimiento ambulatorio constatándose función renal normal.

\section{SCUSI ÓN}

El SUH atípico o D (-) comprende un conjunto de condiciones clínicas más raras y de peor pronóstico que el SUH típico o D (+). El SUH puede ser producido por bacterias, virus, drogas, embarazo y posparto, así como por enfermedades sistémicas ${ }^{(7-11)}$ (Tabla 1 ). 
Tabla 1. Agentes causales del SUH

\begin{tabular}{|l|l|}
\hline \multicolumn{1}{|c|}{ Tipos de SUH } & \multicolumn{1}{c|}{ Agente causal } \\
\hline SUH típico D (+) & $\begin{array}{l}\text { E. coli, Salmonella tiphi, Shigella dysenteriae, } \\
\text { Campilobacter jejuni, Aeromonas, Yersinia }\end{array}$ \\
\hline & $\begin{array}{l}\text { Bacterias: neumococo } \\
\text { Virus: HIV, H1 N1,Epstein Barr, coxackie } \\
\text { Drogas: antineoplásicas, antiplaquetarias, } \\
\text { inmunosupresoras. } \\
\text { Asociado a embarazo y postparto } \\
\text { SUH atípico D ( -) }\end{array}$ \\
Enfermedades sistémicas: LES, esclerodermia \\
Síndrome antifosfolípido \\
Familiar & Idiopáticas \\
\hline
\end{tabular}

El SUH producido por el neumococo corresponde al $4,7 \%$ de los SUH no asociados a STEC, pero se cree que está subdiagnosticado( ${ }^{(7,10)}$. Es una complicación de la enfermedad neumocóccica invasiva ${ }^{(10)}$. Se describe que produce proteinuria e hipertensión arterial en $28 \%$ de los casos, progresión hacia la insuficiencia renal en $23 \%$ y una mortalidad del $11 \%^{(4)}$.

En $85 \%$ de los SUH asociados a neumococo reportados en la literatura en lengua inglesa, el $72 \%$ se asoció a neumonía o empiema y el $29 \%$ a meningitis $^{(10,11)}$. En la literatura se describe que los serotipos ligados al SUH por neumococo son el 14,6B, 9V, 19, 3, 8 y 23F ${ }^{(11)}$. Su patogénesis está ligada a los efectos de la enzima neuraminidasa $(4,6,7)$. Esta enzima remueve el ácido $\mathrm{N}$-acetil hialurónico de la superficie de la membrana celular de los hematíes, plaquetas y glomérulos, exponiendo al antígeno de Thomsen-Friedenreich ( $\mathrm{Ag} T \mathrm{TF})^{(1,6,7)}$. En el ser humano, habitualmente existen anticuerpos contra el Ag TF a partir de los 3 meses de vida, debido 
a que existiría probablemente, flora intestinal con antígenos similares al $\mathrm{Ag} \mathrm{TF}^{(1)}$.

Diversos artículos describen que después de la introducción de la vacuna antineumocóccica conjugada heptavalente, ha disminuido dramáticamente la enfermedad neumocóccica invasiva producida por los serotipos cubiertos por la vacuna, pero se ha visto un aumento de serotipo 19 resistente a ceftriaxona ${ }^{(12-15)}$. Este podría ser el caso de nuestro paciente ya que el mismo recibió dos dosis de vacuna contra neumococo PCV-10, aunque no pudimos obtener serotipo de la bacteria involucrada.

El serotipo 19 está ligado a la producción del SUH a neumococo, por lo que se explicaría el aumento de dicha patología. Si bien la incidencia del SUH a neumococo es baja, algunos autores sugieren que ésta sería mayor si se buscara activamente ${ }^{(10)}$. El SUH secundario a neumococo estaría subdiagnosticado porque no existe una prueba laboratorial específica, por desconocimiento de la patología y por confundirse con $\mathrm{CID}^{(17)}$.

Su reconocimiento precoz es importante porque durante su curso deben evitarse las trasfusiones de glóbulos rojos y plaquetas (que no estén leucorreducidos) y de plasma, dado que esto empeora la morbimortalidad. El inicio precoz de la diálisis peritoneal también mejoraría el pronóstico ${ }^{(8)}$. Se necesita un alto índice de sospecha para realizar un diagnóstico precoz de SUH a neumococo, lo cual es importante para mejorar la morbimortalidad de los pacientes.

\section{REFERENCIAS}

1. Monteverde ML. Síndrome urémico hemolítico. Rev. nefrol. dial. transpl. 2014;34(1): 27-41.

Disponible en: <http://www.scielo.org.ar/scielo.php?script=sci_arttext\&pid=S2346$85482014000100005 \& \operatorname{lng}=\mathrm{es} \& \mathrm{nrm}=$ iso $>$. 
2. Nester CM, Thomas CP. Atypical uremic syndrome: what is it, how is it, diagnosed and how is treated. Hematology Am Soc Hematol Educ Program. 2012;2012:617-25.

3. Campistol J M, Arias M, Ariceta G, Blasco M, Espinosa M, Grinyó J M, et al. An update for atypical haemolytic uraemic syndrome: Diagnosis and treatment. A consensus document. Nefrologia. 2013;33(1):27-45.

4. Fabregas Martori A, Moraga-Llop F, Nieto Rey J, Figueras Nadal C, Soler Palacios G, Roqueta Mas J. Enfermedad neumocóccica invasiva y síndrome urémico hemolítico. An Pediatr (Barc). 2008;68(3):269-72.

5. Silvarino R, Perez G, Canzani O, Larre Borjes P, Acosta N, Noboa O. Sindrome urémico hemolítico atípico: una entidad subdiagnosticada. Rev Med Urug 2014;30(1):56-64.

6. Grisaru S. Management of hemolytic-uremic syndrome in children. Int J Nephrol Renovasc Dis. 2014; 12(7):231-239

7. Noris M, Remuzzi G. Hemolytic uremic syndrome. J Am Soc Nephrol 2005, 16: 1035-1050.

8. Lee CF, Liu SC, Lue KH, Chen JP, Sheu JN. Pneumococcal pneumonia with empyema and hemolytic uremic syndrome in children: report of three cases. J Microbiol Immunol Infect. 2006; 39(4):348-52.

9. Boyer O, Niaudet P. Hemolytic uremic syndrome: new developments in pathogenesis and treatment. Int J Nephrol. 2011;2011:1-10.

10. Copelovitch L, Kaplan BS. Streptococcus Pneumoniae-associated hemolytic uremic syndrome. Pediatr Nephrol 2008; 23: 1951-1956.

11. Niaudet P. Overview of uremic hemolytic syndrome in children. In: Uotodate, Matto TK(Ed) UpToDate, Waltham, MA, 2016:11 p.

12. Vanderkooi OG, Kellner JD, Wade AW, Jadavji T, Midgley JP, Louie T, et al. Invasive Streptococcus Pneumoniae Infection causes Hemolytic Uremic Syndrome: Two Recent Cases. Can J Infect Dis. 2003 Nov; 14(6): 339-43. 